\title{
Active colonisation of disturbed sediments by deep-sea nematodes: evidence for the patch mosaic model
}

\author{
Fabiane Gallucci ${ }^{1, *}$, Tom Moens $^{2}$, Ann Vanreusel $^{2}$, Gustavo Fonseca $^{1}$ \\ ${ }^{1}$ Alfred Wegener Institute for Polar and Marine Research, Am Handelshafen 12, 27570 Bremerhaven, Germany \\ ${ }^{2}$ Marine Biology Section, Biology Department, Ghent University, Krijgslaan 281 (S8), 9000 Gent, Belgium
}

\begin{abstract}
An on-board experiment was performed during a research cruise to investigate the ability of deep-sea nematode species to actively colonise defaunated sediments. Small cylinders of $500 \mu \mathrm{m}$ wire mesh filled with defaunated sediment were inserted into microcosms containing sediment with indigenous meiofauna collected from $1300 \mathrm{~m}$ depth in the Arctic Ocean. The defaunated sediments were either enriched with the diatom Thalassiosira weissflogii, or remained unenriched. Samples from the defaunated sediment were taken after 9 and $17 \mathrm{~d}$. As controls, microcosms with sediment containing the indigenous meiofauna but without an internal cylinder were also sampled at each time interval. Nematodes colonised both enriched and unenriched sediments with abundances of up to $20 \%$ of the controls. Irrespective of the time of sampling, abundance and number of species were significantly higher in the enriched treatment, suggesting that the presence of food enhances colonisation and resilience. Nematode assemblages in the defaunated sediments were species-rich and differed from the controls. The majority of colonising species were rare or undetectable in the controls, suggesting that episodic disturbances may be necessary for their persistence in deep sea sediments. Colonisation was in part determined by species characteristics such as size and motility. At the same time, a large number of different species colonised the empty cylinders, resulting in poor similarity in community composition between replicates, particularly between samples enriched with diatoms. Our results indicate a poor predictability of community composition of recently disturbed sediments despite highly reproducible abundance and diversity patterns and lends experimental support to the existence of a spatio-temporal mosaic that emerges from highly localised colonisation patterns.
\end{abstract}

KEY WORDS: Infauna migration $\cdot$ Disturbance $\cdot$ Patch dynamics $\cdot$ Microcosm experiments $\cdot$ Sediment Deep-sea $\cdot$ Nematodes

\section{INTRODUCTION}

Deep-sea soft-sediment communities are well known to be extremely species-rich (Grassle \& Maciolek 1992). This high species richness, however, contrasts with the apparent physical homogeneity of the deep-sea environment compared with other highly diverse habitats. Mechanisms to explain this paradox have been the subject of speculation for decades and, as a result, a number of hypotheses have been proposed (Snelgrove \& Smith 2002). One of these is the patch-mosaic model, in which small-scale patches of organic matter and disturbance create microhabitats in space and time, providing opportunity for colonisation. These patches are expected to involve highly localised successions of species depending on the pattern of colonisation and, therefore, allow an overall coexistence of large numbers of species (Grassle \& Sanders 1973). To elucidate the functioning of such mosaic systems, one must understand the mechanisms and rates of arrival of new organisms into disturbed patches. Therefore, basic knowledge of rates and patterns of faunal colonisation and succession is of major importance in understanding the processes structuring the 
highly diverse communities associated with deep-sea sediments (Gage 1991).

The applicability of the patch-mosaic model to deepsea communities has gained indirect support from the growing body of literature on patchiness in the deep sea (see reviews by Rice \& Lambshead 1994, Snelgrove $\&$ Smith 2002). Among others, the most important factors determining the patchiness of deep-sea environments are (1) the spatio-temporal patchiness of organic input against a background of low productivity, and (2) sporadic small-scale disturbance events occurring against a background of relative constancy (Grassle \& Morse-Porteous 1987). The patchy input of organic matter to the deep sea has been regarded as both a disturbance and a source of different kinds of separated ephemeral food sources benthic organisms can colonise (Smith 1986, Grassle \& Morse-Porteous 1987). Small-scale physical disturbances $\left(<0.01 \mathrm{~m}^{2}\right.$, Jumars 1976) are mainly caused by crawling, burrowing and feeding activities of larger animals and are best seen as sporadic events in a discrete circumscribed area, resulting in nonselective mortality of local populations and, therefore, in space for colonisation (Grassle \& Morse-Porteous 1987). In both cases, new habitats create opportunities for benthic organisms to colonise. In the comparatively stable and low energy environment of the deep sea, such patches persist much longer and can potentially be used by a broader spectrum of organisms than in hydrodynamically more energetic shallow-water environments (Thistle 1981, Gage 1996, Snelgrove \& Smith 2002).

Although dispersal and colonisation processes of deep-sea macrofauna have been extensively studied (Grassle 1977, Levin \& Smith 1984, Desbruyères et al. 1985, Smith 1985, Grassle \& Morse-Porteous 1987, Snelgrove et al. 1992, 1996, Levin \& Di Bacco 1995), virtually nothing is known about these mechanisms in deep-sea nematodes, the most abundant and probably, at the local scale, the most species-rich metazoan group in deep-sea sediments (Lambshead 1993). Given the differences in lifestyles and dispersal abilities between macrofauna and meiofauna, it is quite conceivable that colonisation processes differ between the groups (Warwick 1984, Snelgrove \& Smith 2002). Evidence from shallow-water studies suggests that, while fast meiofaunal colonisation of large-scale defaunations, where immigration distances are long, are dominated by (passive) water column processes, active infaunal migration of nematodes can be more important for the colonisation of small-scale defaunations (Chandler \& Fleeger 1983, Schratzberger et al. 2004). Due to the generally low hydrodynamics of most deep-sea environments (Munk 1970, Tyler 1995) and the small-scale nature of disturbances (Jumars 1976, Thistle 1978), it is conceivable that infaunal migration processes may be important in determining the smallscale temporal and spatial heterogeneity in deep-sea nematode assemblages.

To investigate active migration by deep-sea nematodes towards open patches, a small-scale laboratory experiment was performed. The experiment aimed at understanding whether deep-sea nematodes can actively colonise small patches of phytodetritus and disturbance and, if so, following which patterns. On the one hand, colonisation patterns may be largely dictated by stochastic effects, with each species having an intrinsically similar potential to colonise a new patch. In this scenario, stochastic effects will play an important role in determining the species composition of small patches of open sediment habitats, and the final stages of colonisation will be rather unpredictable (Gage 1996). Alternatively, disturbed patches may be colonised by a suite of species following more predictable patterns and determined by species characteristics (deterministic factors) such as their motility and colonisation ability (Horn 1981). In particular, we tested the following alternative hypotheses: $\left(\mathrm{H}_{1}\right)$ Deep-sea nematodes actively migrate towards defaunated patches; $\left(\mathrm{H}_{2}\right)$ Active migration is species-specific, i.e. some species may be more efficient than others and, therefore, colonisation might be not entirely random; $\left(\mathrm{H}_{3}\right)$ Colonisation is dependent on nematode size, i.e. larger nematodes will have higher mobility (Schratzberger et al. 2004) and consequently a better colonisation ability; $\left(\mathrm{H}_{4}\right)$ The presence of high-quality food (in the form of diatoms) enhances rates of colonisation, i.e. food acts as an attractant for nematodes and can be sensed from a distance (Höckelmann et al. 2004); and $\left(\mathrm{H}_{5}\right)$ The presence of high-quality food supports higher abundances and number of nematode species over time as detritus-enriched deep-sea sediments generally support higher abundances of meiofaunal organisms (Tietjen et al. 1989, Gallucci et al. 2008) and a larger number of coexisting species (Lambshead et al. 2002, Fonseca \& Soltwedel 2007).

\section{MATERIAL AND METHODS}

Sediment preparation. Field sampling: Arctic deepsea sediments were collected from $1300 \mathrm{~m}$ water depth in the Fram Strait, west of Spitsbergen (approximately $79^{\circ} \mathrm{N}, 4^{\circ} \mathrm{E}$ ) using a multiple corer (MUC). The upper $5 \mathrm{~cm}$ of 5 cores (originating from a single multicorer deployment) were transferred into a bucket and homogenized by gentle stirring with a spatula to reduce initial variability between microcosms. Homogenized sediments containing meiofauna were then used to fill plastic containers $(5 \mathrm{~cm}$ diameter, $11 \mathrm{~cm}$ height) up to $3 \mathrm{~cm}$ height. Sediments were very fine 
and characterised by a predominance of silt (55\%) and clay $(40 \%)$.

Defaunation and enrichment of sediment: The lower part of the MUC-cores (below $8 \mathrm{~cm}$ sediment depth) was sampled and subsequently defaunated by freezing twice to $-20^{\circ} \mathrm{C}$ for $12 \mathrm{~h}$ and subsequent thawing at room temperature. Part of the defaunated sediment was enriched with freeze-dried Thalassiosira weissflogii, equivalent to $1 \mathrm{~g}$ organic $\mathrm{C} \mathrm{m}^{-2}$, to simulate a disturbed patch enriched with phytodetritus (enriched treatment). Prior to the experiment, the centric diatom T. weissflogii was cultured at $15^{\circ} \mathrm{C}$ with a photoperiod of $12 \mathrm{~h}$ light:12 h dark in artificial seawater amended with f/2 medium (Guillard 1975). The cultures were harvested via centrifugation after approximately $14 \mathrm{~d}$ and then freeze-dried. The freeze-dried diatoms were added to the sediment and gently mixed to reach a homogeneous distribution. The remaining defaunated sediment did not receive any addition and was used to simulate a disturbed patch with no organic enrichment (unenriched treatment).

Experimental design. The experimental design and set-up were adapted from Schratzberger et al. (2004). A small cylinder $(1.6 \mathrm{~cm}$ diameter, $5 \mathrm{~cm}$ height) of $500 \mu \mathrm{m}$ mesh filled with either enriched or unenriched defaunated sediment was inserted into the centre of plastic containers (5 $\mathrm{cm}$ diameter, $11 \mathrm{~cm}$ height) that had been filled up to $3 \mathrm{~cm}$ height with sediments containing indigenous meiofauna (Fig. 1). The $500 \mu \mathrm{m}$ mesh was used to provide direct lateral access to nematodes burrowing infaunally from the adjacent sediment.

The internal cylinder consisted of a $500 \mu \mathrm{m}$ wire mesh, open at the top (Fig. 1a). The bottom of the cylinder was closed with Parafilm to prevent sediment particles from leaking through the base. The cylinder was filled with the defaunated sediment (enriched or unenriched) and then carefully pushed into the plastic con-
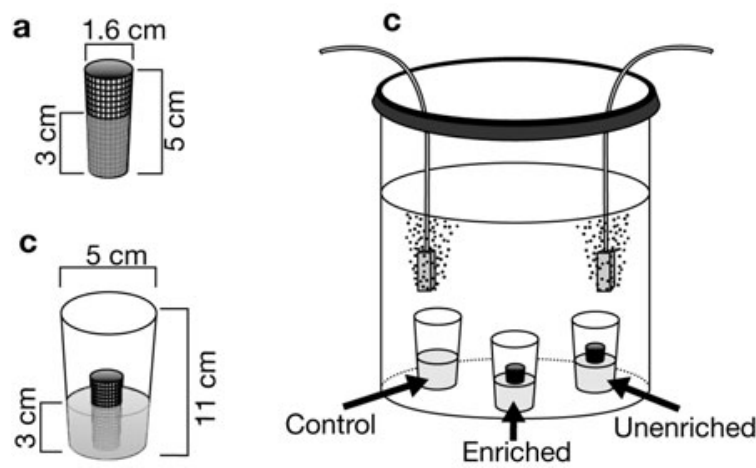

Fig. 1. Schematic drawing of the experimental set up: (a) $500 \mu \mathrm{m}$ mesh cylinder containing enriched or unenriched sediment from $1300 \mathrm{~m}$ water depth, (b) container with indigenous meio-fauna into which mesh cylinder was inserted, (c) aerated buckets tainer filled with the deep-sea sediments containing meiofauna (Fig. 1b). To avoid sediment exchange and passive colonisation by nematodes during the experimental set-up, the cylinder was initially covered by a thin plastic tube. The plastic container and mesh cylinder were then carefully filled with filtered $(0.2 \mu \mathrm{m})$ seawater from the local habitat and haphazardly placed in larger buckets (30 cm diameter) (Fig.1c). The buckets were then filled with filtered seawater and constantly aerated by means of airstones. Once the sediment in both compartments had settled, the plastic tube was pulled out carefully to start the experiment. Controls, consisting of plastic containers filled with the sediment containing meiofauna, but without mesh cylinders, were also placed in the larger aerated buckets (Fig. 1c). The experiment was carried out on board the RV 'Maria S. Merian' (cruise MSM/2) at $1^{\circ} \mathrm{C}$ in the dark.

A total of 22 experimental units (plastic containers with or without internal cylinder) were set up: 8 experimental units for the enriched treatment, 8 for the unenriched treatment and 6 for the controls. These units were distributed over 4 buckets so that each bucket contained experimental units of each treatment. Sampling took place after 9 and $17 \mathrm{~d}$. On each occasion, we sampled 4 replicates of the enriched treatment, 4 replicates of the unenriched treatment and 3 replicates of the control. Each replicate consisted of an entire experimental unit. During sampling, plastic containers were first carefully removed from the larger buckets. Following this, the internal mesh cylinders were pulled out and the sediment transferred into small pots. Controls were sampled using a syringe of the same internal diameter as the cylinders $(1.6 \mathrm{~cm}$ diameter samples down to $3 \mathrm{~cm}$ depth). To characterise the fauna prior to the start of the experiment and verify the efficiency of the defaunation, 4 samples from the homogenized sediment containing meiofauna and 4 samples from the defaunated sediment were taken at the start of the experiment (Day 0).

Sample processing. All samples were transferred to plastic pots and fixed in $4 \%$ formalin. In the laboratory, samples were washed through a $32 \mu \mathrm{m}$ sieve and meiofauna extracted by flotation with Ludox TM50 (Heip et al. 1985). After staining with Rose Bengal, all nematodes were picked out, evaporated to anhydrous glycerol and mounted on permanent slides for identification. Nematodes were identified to genus level and further separated into species or putative morphospecies. Body length (excluding filiform tails) and maximal width of all nematodes were measured using an image analyzer (AnalySIS 3.0). Nematode dry weight was calculated with Andrassy's formula (Andrassy 1956): wet weight $(\mu g)=$ length $(\mu \mathrm{m}) \times$ width $^{2}(\mu \mathrm{m}) / 16 \times 10^{5}$. A dry-to-wet weight ratio of 0.25 was assumed. 
Data analyses. One-way ANOVA was applied to assess differences in total nematode abundance, number of species and Shannon-Wiener diversity indices $\left(\mathrm{H}^{\prime}, \log _{\mathrm{e}}\right)$ between the controls (homogenized sediment) at the different time intervals (Day 0 and after 9 and $17 \mathrm{~d}$ ). Differences in nematode abundance, number of species and Shannon-Wiener diversity indices between treatments and time were analysed using a 2-way ANOVA with 'treatment' (enriched and unenriched) and 'time' (9 and $17 \mathrm{~d}$ ) as fixed factors. Homogeneity of variances was assessed with Cochran's C-test (Sokal \& Rohlf 1995). No data transformation was necessary for either the 1-way or the 2-way ANOVA. Tukey's HSD multiple comparison tests were used when significant interactions were detected ( $\mathrm{p}<$ 0.05; Sokal \& Rohlf 1995).

Non-parametric multivariate analysis of variance, PERMANOVA (Anderson 2001), was used to test for significant 'treatment', 'time' and 'treatment' vs. 'time' effects on nematode assemblage structure. This method allows testing for multivariate interaction terms based on a similarity measure of choice and a nonparametric permutational procedure for the test (McArdle \& Anderson 2001). The analysis was done on Bray-Curtis distances calculated from $\log (x+1)$ transformed data using the FORTRAN program PERMANOVA (Anderson 2005). The test was done using unrestricted permutation of raw data (e.g. Manly 1997) with 4999 random permutations. To visualize the multivariate structure of the nematode assemblages, nonmetric multi-dimensional scaling ordination (MDS) was performed based on the same Bray-Curtis similarity matrix used for PERMANOVA. The variability among replicate samples was analyzed using the multivariate index of dispersion (MID) (Warwick \& Clarke 1993). To determine the contribution of individual species to the average Bray-Curtis dissimilarity between treatments, the similarities percentages (SIMPER) (Clarke \& Warwick 2001) procedure was applied to nematode relative abundances. Data on relative abundances were used for the assessment of which species contributed to the dissimilarity in the structure of nematode assemblages between control and defaunated sediments, irrespective of the large differences observed in absolute abundances. Nematodes were pooled into biomass and morphometric classes (length, width and length/width) on a $\log _{2}$ geometric scale. Biomass size spectra for controls and samples from the internal cylinder were created by plotting curves of nematode cumulative percentage abundance versus biomass classes. For the morphometric classes, we plotted the proportion of individuals against geometric classes of length, width and length/ width. Differences in the distributions of nematode morphometrics between controls and defaunated sediments were assessed with a chi-squared test.

\section{RESULTS}

\section{Microcosm efficiency}

A total of 165 species were identified in the controls. The 5 most abundant species altogether accounted for $20.8 \%$ of the total community (Monhystrella sp.1: 6.4\%, Amphimonhystrella sp.1: 4.5\%, Leptolaimus sp.1: $3.7 \%$, Sabatieria sp.1: $3.2 \%$ and Thalassomonhystera sp.1: 3\%). The other 160 species each represented less than $1 \%$ of the total nematode abundances.

Over the course of the experiment, nematode abundances, number of species and diversity in the controls did not differ from the a priori sediment samples (Fig. 2), neither did nematode community structure (Fig. 3a, Table 1).

\section{Colonisation}

A total of 93 species (56\% of the total number of species in the controls) colonised the defaunated sediments. Nematode abundances in the internal cylinders corresponded to approximately $5 \%$ (9 d unenriched) to $20 \%$ (9 d enriched) of mean nematode abundances in the controls. Sabatieria sp.1 and Leptolaimus sp.1 were
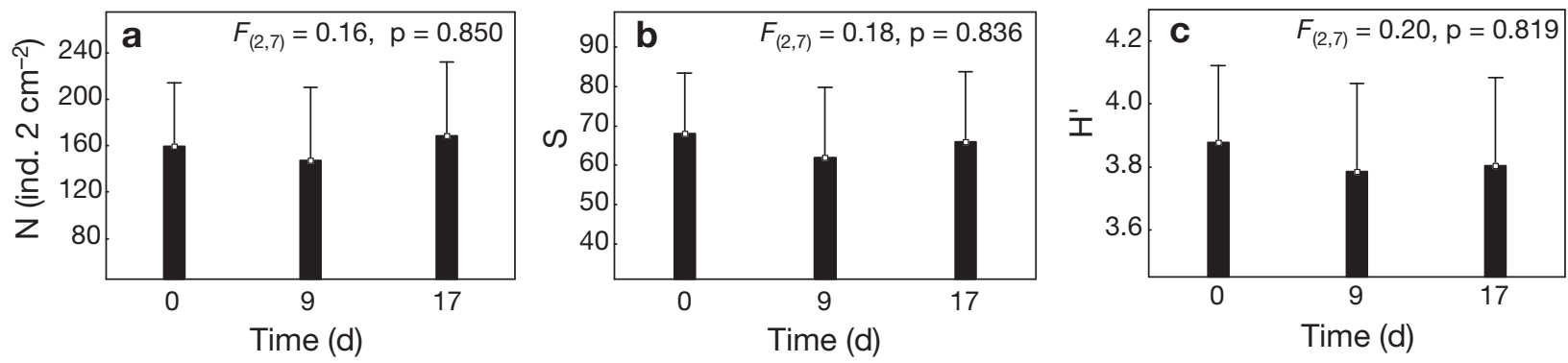

Fig. 2. Mean and $95 \%$ confidence interval for (a) nematode abundances (N), (b) number of species (S), and (c) Shannon-Wiener species diversity index $\left(\mathrm{H}^{\prime}\right)$ in the controls prior to the start of the experiment (Day 0 ) and after 9 and $17 \mathrm{~d}$ 


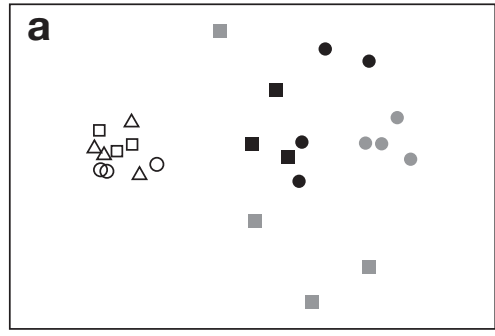

2D Stress: 0.12

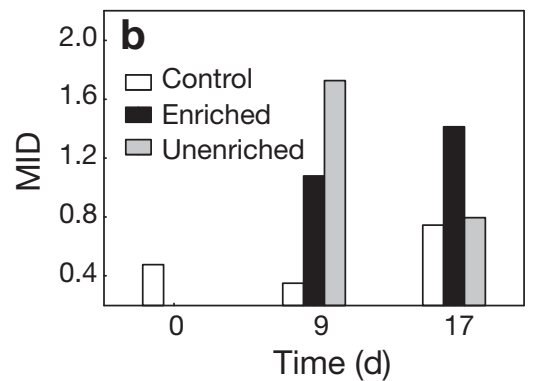

Fig. 3. (a) Non-parametric multi-dimensional scaling ordination for nematode assemblages from the controls (open symbols), and enriched (black symbols) and unenriched (grey symbols) treatments at the time intervals sampled over the duration of the experiment: Day 0 (triangles); $9 \mathrm{~d}$ (circles); $17 \mathrm{~d}$ (squares). (b) Multivariate index of dispersion for the control and the enriched and unenriched treatments at Day 0, after $9 \mathrm{~d}$ and after $17 \mathrm{~d}$

Table 1. Non-parametric multivariate analysis of variance of nematode species abundances, based on the Bray-Curtis similarity measure. Values in bold indicate significant differences at $\mathrm{p}<0.05$

\begin{tabular}{|lrrrrr|}
\hline Factor & df & \multicolumn{1}{c}{ SS } & MS & $F$ & \multicolumn{1}{c|}{ p } \\
\hline Treatment & 2 & 25549 & 12774 & 7.14 & $<\mathbf{0 . 0 1}$ \\
Time & 1 & 3962 & 3962 & 2.21 & $\mathbf{0 . 0 3}$ \\
Treatment $\times$ Time & 2 & 6390 & 3195 & 1.78 & $\mathbf{0 . 0 3}$ \\
Residual & 18 & 32202 & 1789 & & \\
Total & 23 & 68105 & & & \\
\hline
\end{tabular}

Pairwise post hoc comparison

\begin{tabular}{lccccc} 
& \multicolumn{2}{c}{ Time } & \multicolumn{2}{c}{$17 \mathrm{~d}-$} \\
\cline { 2 - 5 } Treatment & $t$ & $\mathrm{~d}$ & & $\mathrm{p}$ & $\mathrm{p}$ \\
\hline Control $\times$ Unenriched & 1.97 & $\mathbf{0 . 0 3}$ & 3.44 & $\mathbf{0 . 0 2}$ \\
Control $\times$ Enriched & 2.97 & $\mathbf{0 . 0 2}$ & 2.27 & $\mathbf{0 . 0 2}$ \\
Enriched $\times$ Unenriched & 1.13 & 0.28 & 1.41 & $\mathbf{0 . 0 4}$
\end{tabular}

\begin{tabular}{lcccccc} 
& \multicolumn{4}{c}{ Control } & \multicolumn{2}{c}{ Treatment } \\
Time & $t$ & $\mathrm{p}$ & $t$ & $\mathrm{p}$ & $t$ & $\mathrm{p}$ \\
\hline $9 \mathrm{~d} \times 17 \mathrm{~d}$ & 1.31 & 0.14 & 1.47 & $\mathbf{0 . 0 2}$ & 1.32 & $\mathbf{0 . 0 3}$ \\
\hline
\end{tabular}

ues (Tukey's HSD test, $\mathrm{p}<0.01$ ) were observed after $17 \mathrm{~d}$ in the unenriched treatments (Fig. 4)

Nematode trophic structure (according to the classification of feeding type based on mouth morphology by Wieser 1953) did not differ among treatments or between treatments and controls, nor did it differ over time $(p>0.05)$. Selective deposit feeders (1A, Wieser 1953) represented $38 \%$ and $45 \%$ of the total nematodes in the controls and defaunated sediments, respectively. Nonselective deposit feeders (1B) represented 37 and $35 \%$ of the total nematodes in control and defaunated sediments, followed by epigrowth feeders (2A, ca. 15 and $21 \%$ ) and predators/omnivores (2B, ca. 5 and $4 \%$ ).

Non-parametric PERMANOVA on nematode species abundance data showed a significant interaction between the factors treatment and time (Table 1). Individual pair-wise comparisons of effects of treatments for each time interval showed that, while nematode assemblage structure in the controls differed from enriched and unenriched sediments at both sampling times, significant differences between enriched and unenriched sediments were detected only after $17 \mathrm{~d}$ (Table 1). This was mainly due to the lower nematode abundances and number of species in the unenriched treatment. The multivariate post hoc comparisons still showed that controls did not differ over the course of the experiment, while nematode assemblages from enriched and unenriched treatments differed be-

the most abundant species in both treatments (17 and $20 \%$, respectively). The other colonisers each represented less than $2 \%$ of the total and were mainly rare or even undetected in the control samples.

Neither nematode abundance nor total number of species showed a significant interaction for the combined effect of treatment vs. time (Fig. 4, Table 2). Total nematode abundance was significantly higher in enriched sediments and did not differ between 9 and 17 d (Fig. 4, Table 2). Total number of nematode species in the internal cylinders was significantly higher in enriched sediments, but showed a significant decrease with time (Fig. 4, Table 2). Nematode diversity showed a borderline significant interaction of treatment vs. time ( $p=0.057$ ) (Table 2$)$, and significantly lower val- tween 9 and $17 \mathrm{~d}$ (Table 1, Fig. 3a). In addition, the multivariate index of dispersion showed that replicates within treatments were highly variable when compared with the controls (Fig 3b). Unenriched samples were more variable on the first sampling occasion (9 d) and then became more similar with time. In contrast, in samples enriched with diatoms, variability between replicates increased with time (Fig. 3b).

Results from SIMPER analysis based on the relative abundance data revealed that the differences between control and defaunated sediments were mainly due to the higher proportions of Sabatieria sp.1 and Leptolaimus sp. 1 in the defaunated sediments. These 2 species together accounted for 19 and $24 \%$ of the total dissimilarity between the control and the enriched (total 

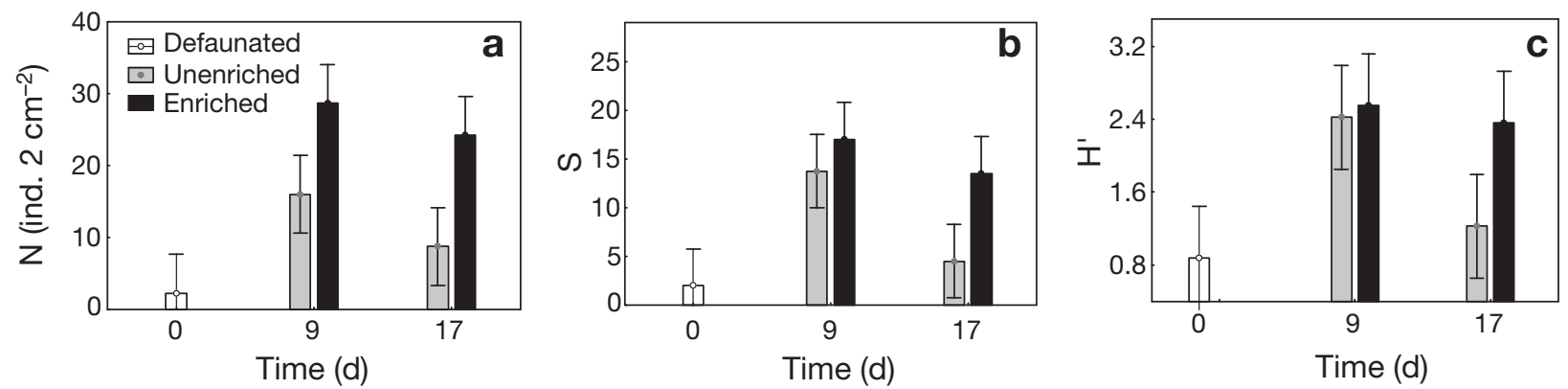

Fig. 4. Mean and 95\% CI for (a) nematode abundances (N), (b) number of species (S), and (c) Shannon-Wiener species diversity index $\left(\mathrm{H}^{\prime}\right)$ in the enriched and unenriched treatments after 9 and $17 \mathrm{~d}$

Table 2. 2-way ANOVA of differences in nematode abundance, number of species and species diversity between treatments (unenriched and enriched), time (9 and $17 \mathrm{~d}$ ) and treatment vs. time. Values in bold indicate significant differences at $\mathrm{p}<0.05$

\begin{tabular}{|lrrrr|}
\hline & df & MS & $F$ & p \\
\hline Abundance & & & & \\
Treatment & 1 & 792.4 & 25.3 & $<\mathbf{0 . 0 0 1}$ \\
Time & 1 & 135.7 & 4.3 & 0.061 \\
Treatment $\times$ Time & 1 & 8.1 & 0.3 & 0.619 \\
Residual & 12 & 31.3 & & \\
Number of species & & & & \\
Treatment & 1 & 156.2 & 10.2 & $\mathbf{0 . 0 0 8}$ \\
Time & 1 & 169.0 & 11.0 & $\mathbf{0 . 0 0 6}$ \\
Treatment $\times$ Time & 1 & 30.2 & 1.9 & 0.185 \\
Residual & 12 & 15.3 & & \\
Species diversity (H') & & & & \\
Treat & 1 & 1.6 & 6.9 & $\mathbf{0 . 0 2 1}$ \\
Time & 1 & 1.9 & 8.5 & $\mathbf{0 . 0 1 3}$ \\
Treatment $\times$ Time & 1 & 1.0 & 4.4 & 0.057 \\
Residual & 12 & 0.2 & & \\
\hline
\end{tabular}

dissimilarity $=83.3$ ) and unenriched (total dissimilarity $=87.7$ ) sediments, respectively. The complete absence of Monhystrella sp.1 (a dominant species in the controls) from both enriched and unenriched sediments also contributed to the dissimilarities between treatments and control (3.7 and 3.9\% for enriched and unenriched treatments, respectively). Other species each contributed less than $3 \%$ to the total dissimilarity between treatments and controls.

\section{Nematode biomass and morphometry}

In the controls, about $90 \%$ of the nematode assemblage consisted of individuals with very low biomass (<2.5 $\mu \mathrm{g}$, biomass classes 1 and 2; Fig. 5a). In the colonised sediments, this class represented less than $80 \%$ of the total assemblage and there was a significant increased contribution of nematodes with larger biomass $(>2.5 \mu \mathrm{g})$ when compared with the controls (1-way ANOVA, p < 0.05). Cumulative nematode biomass confirmed a higher proportion of individuals with larger biomass in colonised (enriched and unenriched) sediments (Fig. 5b).

The distribution of nematode morphometric (length/ width) classes assumed a bimodal shape typical of deep-sea assemblages. The first mode represents the nematodes with a stout body shape and the second the slender nematodes (Fig. 6a). Both morphometric class modes of the colonising nematodes (in both enriched and unenriched treatments) were located towards the right, indicating that colonisation was mainly by larger individuals (Fig. 6a). Nematode assemblages from the colonised sediments were characterized by greater body length and also body width $\left(\chi^{2}\right.$ test, $\left.\mathrm{p}<0.01\right)$ (Fig. 6b,c).

\section{DISCUSSION}

\section{Microcosm efficiency}

Experiments potentially provide the strongest test for existing hypotheses, but their validity may be constrained by the artificial manipulation of nature (Quinn $\&$ Keough 2002). In the present experimental design, the pre-treatment of sediments (i.e. mixing different cores and sediment layers) is likely to have changed the nematode species composition inside our microcosms compared with the natural field situation, which we did not analyse. Nevertheless, the community structure and its dominant genera present at the beginning of the experiment, after mixing, were highly representative of deep-sea nematode communities at the study site (Hoste 2006, Gallucci et al. 2008) and other deep-sea sites (Soetaert \& Heip 1995), thus providing a highly relevant case study. A second potential artefact is associated with the enclosure of the deepsea nematode assemblages in microcosms. It is known from experiments with shallow-water and intertidal 
Fig. 5. (a) Relative abundance and (b) cumulative abundance of nematodes in each geometric size class in the controls and in the enriched and unenriched treatments. Note the break in the scale in the $y$-axis in (a)
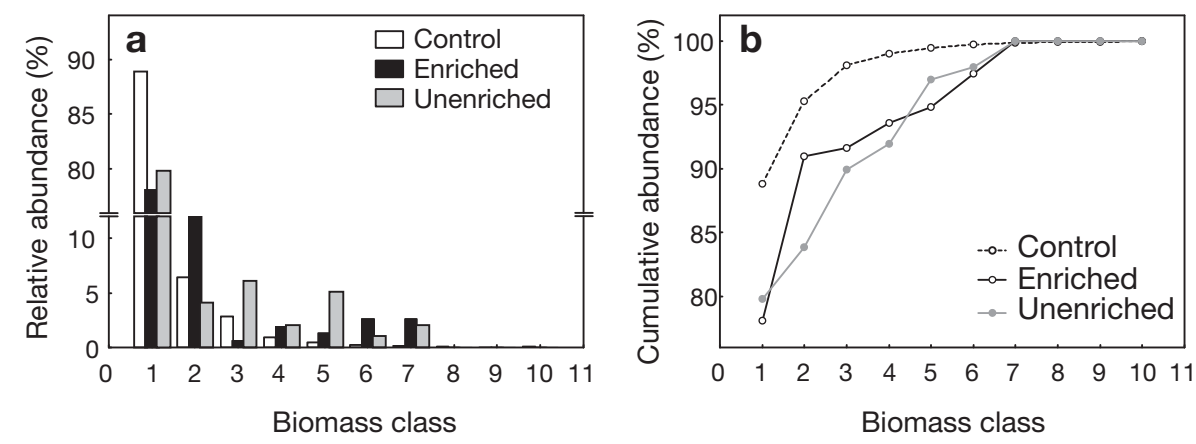

nematodes that microcosms can cause significant changes in the assemblages over time (Schratzberger \& Warwick 1999, Schratzberger et al. 2004). In the present study, however, no significant changes were observed in nematode abundances, number of species, species diversity or community structure in the control treatments during the $17 \mathrm{~d}$ of the experiment, demonstrating the potential of short-term microcosm experiments with deep-sea nematodes. Given the difficulty of conducting in situ experiments in the deep sea and consequently the slow progress of testing specific deep-sea hypotheses, other processes and factors affecting deep-sea nematode assemblages on a small scale may be amenable to experimental testing under laboratory conditions.

\section{Colonisation}

The infaunal colonisation of defaunated sediments observed in our experiment confirms our first hypothesis $\left(\mathrm{H}_{1}\right)$ that deep-sea nematodes can actively colonise open patches, indicating their ability to respond within a time frame of a few days (or less) following a smallscale disturbance. The proportion of nematodes colonising defaunated sediments (from 5\% to $20 \%$ after $9 \mathrm{~d}$ ), although relatively low, was similar to, or at the lower end of, reports on infaunal migration by coastal nematodes at comparable (Chandler \& Fleeger 1983, Zhou 2001, Schratzberger et al. 2004) or longer (Ullberg \& Ólafsson 2003a) time-scales. These results suggest that infaunal colonisation rates in both environments may be comparable, in contrast to general suggestions about lower colonisation rates in the deep sea (Grassle 1977, Gage 1991). The number of species that colonised the defaunated sediments in our experiment was relatively high, but still comparable in terms of proportion of nematode species relative to the source assemblage (controls) to 2 shallow-water studies from which information on species composition was available (Schratzberger et al. 2004, Ullberg \& Ólafsson 2003a).

Nematode assemblages colonising the defaunated sediments were very different from the controls, indicating that species association upon initial colonisation is probably not merely a result of random processes. Indeed, some species did colonise more efficiently, confirming our second hypothesis $\left(\mathrm{H}_{2}\right)$ that active migration is species-specific. Sabatieria sp.1 and Leptolaimus sp.1, for example, reached elevated proportions after $9 \mathrm{~d}$ in both enriched and unenriched sediments compared with control samples, and remained
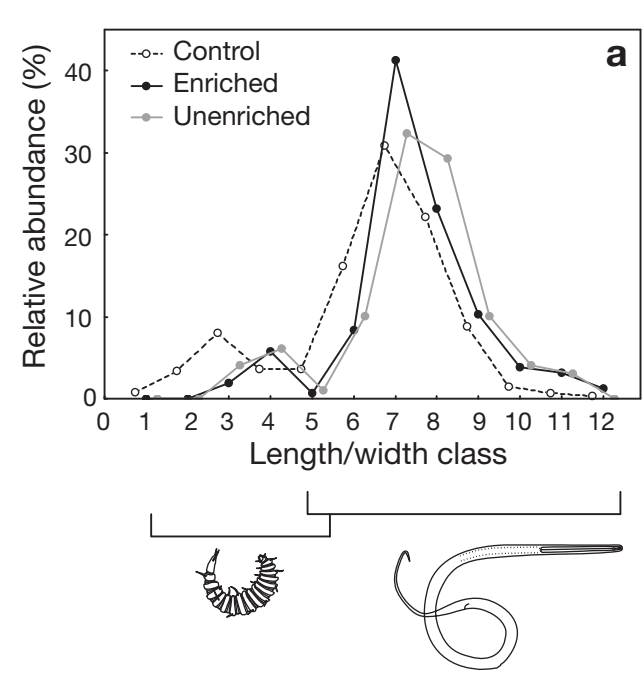
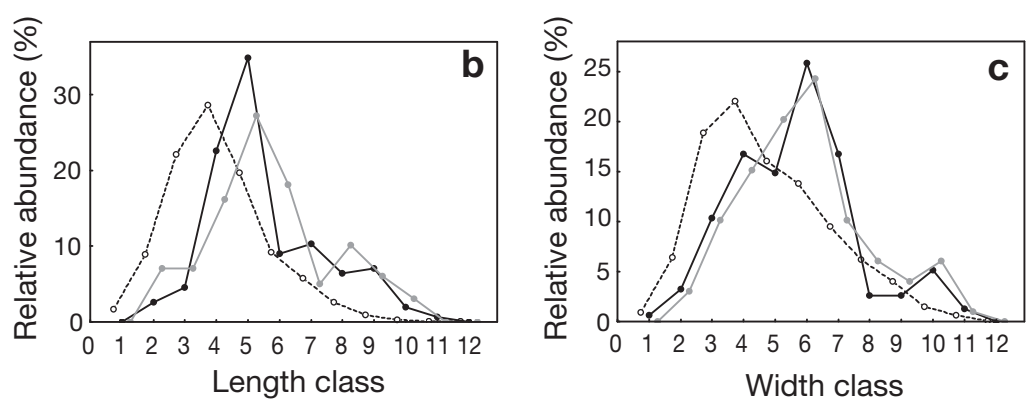

Fig. 6. Relative abundance of nematodes in each (a) length/width geometric class, (b) length geometric class and (c) width geometric class in the controls and in the enriched and unenriched treatments 
at this proportion over the course of the experiment. Together they accounted for approximately $40 \%$ of all nematodes encountered in the defaunated sediments, compared to only about $3 \%$ in the controls. Both species are deep dwellers, which at our study site preferentially live in deeper anoxic sediment layers (Hoste 2006); they probably have a higher mobility through compacted subsurface sediments that may enable them to access oxygen in the upper layers (Soetaert et al. 2002). This combination of a high tolerance of reduced oxygen conditions with a greater motility may be an important life strategy to compensate for a lesser competitive ability. Several of the most dominant species in this nematode community, for instance, belong to the family Monhysteridae, whose reproductive rates are generally higher and development rates faster than in most other marine nematodes (Heip et al. 1985, Bongers et al. 1991). Interestingly, an investigation on active infaunal movements of subtidal nematodes (30 m water depth) over short distances also found that 1 species of Sabatieria (S. pulchra) and 2 species of Leptolaimus (L. elegans and L. papilliger) were the most successful migrators of all nematode species within the assemblage (Ullberg \& Ólafsson 2003a). These observations from shallow- and deep-water environments clearly indicate a fast colonisation rate (and opportunistic behaviour) of these 2 genera.

The other $60 \%$ of the total nematode assemblage colonising defaunated sediments were made up by species that were rare or even undetected in the controls. This is similar to other studies that have been conducted on the effects of patches on infaunal biodiversity in the deep sea, where a different suite of species tended to dominate disturbances or organic patches relative to the ambient fauna (Kukert \& Smith 1992, Snelgrove et al. 1994). Results from macrofaunal colonisation studies also showed that the colonising fauna were markedly different from the fauna in ambient sediment, and that the most common colonisers were rare or absent from ambient samples (Desbruyères et al. 1980, Smith et al. 1986, Grassle \& Morse-Porteous 1987, Snelgrove et al. 1996). The open space and/or elevated organic matter availability in disturbed patches may act as a competitive release for colonisers, allowing relatively uncommon species to prosper (Kukert \& Smith 1992). Such an efficient response to favourable conditions may guarantee that local extinctions are counterbalanced and may as such be an important life strategy to inhabit a patchily disturbed environment.

In contrast, the predominant nematode species in the controls, Monhystrella sp.1, did not colonise the defaunated sediments in our experiment. This species, like many of the dominant deep-sea species, has a long filiform tail, which has been suggested to be typical for a hemi-sessile life strategy (Riemann 1974). In addition, experiments on deep-sea macrofauna (Desbruyères et al. 1980, Grassle \& Morse-Porteous 1987, Kukert \& Smith 1992, Snelgrove et al. 1994, 1996) have shown that common deep-sea species are poorly adapted to respond to disturbance, suggesting that small-scale patches of disturbance may be less important in the ecology of dominant infaunal species (Smith 1986). This may also apply to dominant deep-sea nematodes (Gallucci et al. 2008). It is important to note, however, that Monhystrella sp.1 is a very small nematode that may have limited active migration ability. Its response to disturbance may involve a completely different strategy (e.g. high reproductive rates) and rely less on motility.

In the defaunated sediments, the size spectrum shifted towards longer and wider nematodes, confirming our third hypothesis $\left(\mathrm{H}_{3}\right)$ that active migration is dependent on nematode size. Larger species typically forage over larger areas than smaller ones, and they can also more easily burrow through the sediment (Wieser 1959, Tita et al. 1999). Therefore, larger nematode body size, and particularly greater width (Tita et al. 1999), probably confers greater colonisation ability via infaunal migration (Schratzberger et al. 2002, 2004). However, smaller nematodes often inhabit the surface sediment layers (Soetaert et al. 2002, Hoste 2006) and may largely depend on passive dispersal for colonisation. Passive dispersal was precluded from the present experimental design due to the absence of bottom currents. Therefore, other experimental designs and/or in situ studies are necessary to elucidate the role of passive versus active migration in patch colonisation by deep-sea nematodes.

The higher nematode abundances observed in the diatom-enriched treatment compared with the unenriched treatment indicate that, at a small scale, nematodes may detect and migrate towards patches of phytodetritus, thus supporting the fourth hypothesis $\left(\mathrm{H}_{4}\right)$. Chemical signals in aquatic environments enable organisms to find food and avoid predators (e.g. Tomba et al. 2001), and there is a general consensus, based on morphological and experimental evidence, that chemotactic factors govern the primary food-finding mechanisms in nematodes (Jensen 1981, Zuckerman \& Jansson 1984, Höckelmann et al. 2004). It is unclear, however, what cues elucidated the response of, for instance, Sabatieria sp.1 and Leptolaimus sp.1 in our experiment. Indeed, the possibility of a 'random walk' behaviour cannot be excluded. Sabatieria sp.1 and Leptolaimus sp.1 colonised both the enriched and unenriched sediments with similar numbers, and neither genus has ever been reported to feed on diatoms. It is possible that they responded to other potential food cues emanating from active bacterial growth on re- 
mains of organisms killed during and decomposed after the freezing-and-thawing process and/or on the diatom detritus. In fact, many nematode species in the controls, as well as the colonisers of both enriched and unenriched sediments, were selective (1A) or nonselective deposit-feeders (1B), which may feed more on bacteria and dissolved organic matter than on diatoms (Wieser 1953). As such, their response to the diatom enrichment may have been indirect. We also cannot exclude the possibility that nematodes were attracted by other, biogeochemical cues. Defaunated sediment in the cylinders originated from deeper sediment layers and, therefore, may well have differed in some biogeochemical characteristics from the surrounding sediments containing meiofauna. Sabatieria sp.1 and Leptolaimus sp.1, for example, often occur in deeper, hypoxic to anoxic sediment layers (Hoste 2006). Hence, some of the observed responses at the species level may relate to factors other than food.

Nevertheless, the establishment of nematode species in the defaunated sediment depended on the presence or absence of diatoms. Mean nematode abundances and number of species remained lower and diversity significantly decreased in the unenriched treatment. The community structure in the unenriched treatment became more homogeneous among replicates since most species disappeared and Leptolaimus sp.1 and Sabatieria sp.1 remained dominant in all replicates. It is likely that species that first colonised these sediments did not find favourable conditions (e.g. appropriate resources) and continued to forage, eventually leaving the internal cylinder. On the other hand, number and diversity of species in enriched sediments were still relatively high after $17 \mathrm{~d}$, confirming our fifth hypothesis $\left(\mathrm{H}_{5}\right)$ that the presence of high-quality food would support higher abundances and diversity of nematodes. Despite abundance and diversity remaining constant, nematode community structure significantly changed from 9 to $17 \mathrm{~d}$ at the enriched treatment. Also, variability between replicates at $17 \mathrm{~d}$ increased, indicating a differential development of the assemblages in the different replicates. Nematode abundances and number of species were rather similar among these replicates, indicating that differences were mainly in species composition. These observations support the hypothesis of the existence of a spatio-temporal mosaic that emerges from highly localised successions (Grassle \& Sanders 1973). While the model of Grassle \& Sanders (1973) states that natural disturbances create a mosaic of patches that have different species compositions depending on their state of recovery, our results indicate that similar patches at the same stage of recovery can also evolve differently; hence, colonisation may be rather unpredictable. This is probably because the deep sea locally and region- ally supports such a large pool of species with diverse abilities to exploit disturbed conditions, resulting in both more numerous and more randomly determined species involved in succession, compared with shallow-water systems (Kukert \& Smith 1992). In our data, this is apparent from the relatively large number of species (93 species) involved in the colonisation of the defaunated sediments. The colonisation patterns observed here, however, represent only the very early stages of succession. Prolonged experimental incubations are required to determine the fate of these early assemblages of colonisers.

Caution is due when extrapolating from the results of this small-scale laboratory experiment to more complex in situ conditions. Although nematode migration through the sediment is important in the colonisation of small-scale defaunations (Chandler \& Fleeger 1983, Schratzberger et al. 2004), in situ colonisation of patches by nematodes may also be significantly influenced by water column processes (Palmer \& Gust 1985, Palmer 1988). Bottom currents may suspend and transport nematodes, particularly those species inhabiting the sediment surface, and may therefore help species to find and colonise suitable patches (Üllberg \& Ólafsson 2003b). Besides, a larger pool of potential colonisers will be available in a natural setting compared to our microcosm. In this scenario, higher abundances are likely to result and a larger number of different species are expected to be involved. Interstitial migration by adult macrofauna as well as settlement of macrofauna larvae is also likely to influence colonisation by nematodes in situ. Finally, colonisation of azoic sediment can vary markedly between patches of different sizes (Smith \& Brumsickle 1989). In the deep sea, different scales of disturbance are likely to occur and, consequently, various colonisation responses might be expected. To better elucidate the complexity of the colonisation of patches by deep-sea nematodes, more elaborate experimental designs and, ideally, in situ experiments are required.

\section{CONCLUSION}

This study provides first insights into the small-scale colonisation of disturbed patches by deep-sea nematodes. It demonstrates that nematode species can actively colonise defaunated sediments within a few days, and that this colonisation is partly dependent on the amount and/or quality of organic detritus present. A relatively large number of species that were mostly rare or even remained undiscovered in the surrounding sediment colonised the defaunated sediments, suggesting that small-scale disturbance contributes to their persistence in deep-sea sediments. Patch coloni- 
sation was in part determined by species characteristics such as size and motility, which are probably intricately linked. At the same time, a large number of different species colonised the experimental patches (empty cylinders) resulting in poor similarity in community composition between replicate samples, particularly between samples seeded with diatom detritus. This indicates a poor predictability of community composition following colonisation of disturbed patches despite highly reproducible abundance and diversity patterns, and lends experimental support to the patch mosaic model.

Finally, this study illustrates the potential of microcosm experiments with deep-sea nematodes. If microcosms prove to be efficient with deep-sea fauna from other regions and water depths, this would be a significant improvement in our ability to test specific hypotheses in such a remote environment. Moreover, such experiments may also provide valuable a priori information for the development of future in situ experiments, which are more costly and difficult to perform.

Acknowledgements. We thank the crew of the RV 'Maria S. Merian' for their support during the summer expedition of 2006 and T. Soltwedel for providing the multicorer samples. Special thanks are due to $M$. Iversen for his valuable help with the diatom cultures. We are grateful to P. Snelgrove and 2 anonymous reviewers for their constructive criticism and helpful comments on an earlier version of the manuscript. F.G. is sponsored by a $\mathrm{PhD}$ fellowship from the Deutscher Akademischer Austausch Dienst (DAAD) and the Helmholtz Association. G.F. is supported by the Brazilian Ministry of Science and Technology (CNPq). T.M. is a postdoctoral fellow with the Flemish Fund for Scientific Research (FWO). This is publication 'awi-n17301' of the Alfred Wegener Institute for Polar and Marine Research, Bremerhaven, Germany.

\section{LITERATURE CITED}

Anderson MJ (2001) A new method for non-parametric multivariate analysis of variance. Aust Ecol 26:32-46

Anderson MJ (2005) PERMANOVA: a FORTRAN computer program for permutational multivariate analysis of variance. Department of Statistics, University of Auckland

Andrassy I (1956) The determination of volume and weight of nematodes. Acta Zool Hung 2:1-15

Bongers T, Alkemanade R, Yeates GW (1991) Interpretation of disturbance-induced maturity decrease in marine nematode assemblages by means of Maturity Index. Mar Ecol Prog Ser 76:135-142

Chandler GT, Fleeger JW (1983) Meiofaunal colonization of azoic estuarine sediment in Louisiania: mechanisms of dispersal. J Exp Mar Biol Ecol 69:175-188

Clarke KR, Warwick RM (2001) Changes in marine communities: an approach to statistical analysis and interpretation. PRIMER-E, Plymouth

Desbruyères D, Deming JW, Dinet A, Khripounoff A (1985) Réactions de l'écosysteme bentique profound aux perturbations: nouveaux résultats expérimentaux. In: Laubier $\mathrm{L}$, Monniot CL (eds) Peuplements profonds du Golfe de Gasgone. Institute Français de Recherche pour l'Exploitation de la Mer, p 193-209
Fonseca G, Soltwedel T (2007) Deep-sea meiobenthic communities underneath the marginal ice zone off Eastern Greenland. Polar Biol 30:607-618

Gage JD (1991) Biological rates in the deep sea: a perspective from studies on processes in the benthic boundary layer. Rev Aquat Sci 5:49-100

Gage JD (1996) Why are there so many species in deep-sea sediments? J Exp Mar Biol Ecol 200:257-286

Gallucci F, Fonseca G, Soltwedel T (2008) Effects of megafauna exclusion on nematode assemblages at a deep-sea site. Deep-Sea Res I 55:332-349

Grassle JF (1977) Slow recolonization of deep-sea sediment. Nature 265:618-619

> Grassle JF, Maciolek NJ (1992) Regional and local diversity estimates from quantitative bottom samples. Am Nat 139: 313-341

Grassle JF, Morse-Porteous LS (1987) Macrofaunal colonization of disturbed deep-sea environments and the structure of deep-sea benthic communities. Deep-Sea Res 34: 1911-1950

Grassle JF, Sanders HL (1973) Life histories and the role of disturbance. Deep-Sea Res I 20:643-659

Guillard RRL (1975) Culture of phytoplankton for feeding marine invertebrates. In: Smith WL, Chanley MH (eds) Culture of marine invertebrate animals. Plenum Press, New York, p 26-60

Heip C, Vincx M, Vranken G (1985) The ecology of marine nematodes. Oceanogr Mar Biol Annu Rev 23:399-489

Höckelmann C, Moens T, Juttner F (2004) Odor compounds from cyanobacterial biofilms acting as attractants and repellents for free-living nematodes. Limnol Oceanogr 49:1809-1819

Horn HS (1981) Succession. In: May RM (ed) Theoretical ecology: principles and applications. Blackwell Scientific Publications, Oxford, p 253-271

Hoste E (2006) Temporal and spatial variability in deep-sea meiobenthic communities from the Arctic Marginal Ice Zone. PhD thesis, Ghent University

> Jensen P (1981) Phyto-chemical sensitivity and swimming behaviour of the free-living marine nematode Chromadorita tenuis. Mar Ecol Prog Ser 4:203-206

Jumars PA (1976) Deep-sea species diversity: Does it have a characteristic scale? J Mar Res 34:217-246

Kukert H, Smith CR (1992) Disturbance, colonization and succession in a deep-sea sediment community: artificialmound experiments. Deep-Sea Res 39:1349-1371

Lambshead PJD (1993) Recent developments in marine benthic biodiversity research. Oceanis 19:5-24

> Lambshead PJD, Brown CJ, Ferrero TJ, Mitchell NJ, Smith CR, Hawkins LE, Tietjen J (2002) Latitudinal diversity patterns of deep-sea marine nematodes and organic fluxes: a test from the central equatorial Pacific. Mar Ecol Prog Ser 236:129-135

Levin LA, Di Bacco C (1995) Influence of sediment transport on short-term recolonization by seamount infauna. Mar Ecol Prog Ser 123:163-175

- Levin LA, Smith CR (1984) Response of background fauna to disturbance and enrichment in the deep-sea: a sediment tray experiment. Deep-Sea Res 31:1277-1285

Manly BFJ (1997) Randomization, bootstrap and Monte Carlo methods in biology. Chapman \& Hall, London

McArdle BH, Anderson MJ (2001) Fitting multivariate models to community data: a comment on distance-based redundancy analysis. Ecology 82:290-297

Munk W (1970) The circulation of the oceans. In: Cloud P (ed) Adventures in earth history. Freeman, San Francisco, CA, p 235-240 
Palmer MA (1988) Dispersal of marine meiofauna: a review and conceptual model explaining passive transport and active emergence with implications for recruitment. Mar Ecol Prog Ser 48:81-91

Palmer MA, Gust G (1985) Dispersal of meiofauna in a turbulent tidal creek. J Mar Res 43:179-210

Quinn GP, Keough MJ (2002) Experimental design and data analysis for biologists. Cambridge University Press, Cambridge

Rice AL, Lambshead PJD (1994) Patch dynamics in the deepsea benthos: the role of a heterogeneous supply of organic matter. In: Giller PS, Hildrew AG, Raffaelli DG (eds) Aquatic ecology: scale, pattern and process. 34th Symp Br Ecol Soc, Blackwell Scientific Publications, Oxford, p 469-499

Riemann F (1974) On hemisessile nematodes with flagelliform tails living in marine soft bottoms and on microtubes found in deep sea sediments. Mikrofauna Meeresboden 40:1-15

Schratzberger M, Warwick RM (1999) Differential effects of various types of disturbances on the structure of nematode assemblages: an experimental approach. Mar Ecol Prog Ser 181:227-236

Schratzberger M, Wall CM, Reynolds WJ, Reed J, Waldock MJ (2002) Effects of paint-derived tributyltin on structure of estuarine nematode assemblages in experimental microcosms. J Exp Mar Biol Ecol 272:217-235

Schratzberger M, Whomersley P, Warr K, Bolam SG, Rees HL (2004) Colonisation of various types of sediment by estuarine nematodes via lateral infaunal migration: a laboratory study. Mar Biol 145:69-78

Smith CR (1985) Food for the deep-sea: utilization dispersal and flux of nekton falls at the Santa Catalina Basin floor. Deep-Sea Res 32:417-442

Smith CR (1986) Nekton falls, low intensity disturbance and community structure of infaunal benthos in the deep sea. J Mar Res 44:567-600

Smith CR, Brumsickle SJ (1989) The effects of patch size and substrata isolation on colonization modes and rates in an intertidal sediment. Limnol Oceanogr 34:1263-1277

Smith CR, Jumars PA, DeMaster DJ (1986) In situ studies of megafaunal mounds indicate rapid sediment turnover and community response at the deep-sea floor. Nature 323: 251-253

Snelgrove PVR, Smith CR (2002) A riot of species in an environmental calm: the paradox of the species-rich deep-sea floor. Oceanogr Mar Biol Annu Rev 40:322-342

Snelgrove PVR, Grassle JF, Petrecca RF (1992) The role of food patches in maintaining high deep-sea diversity: field experiments with hydrodynamically unbiased colonization trays. Limnol Oceanogr 37:1543-1550

Snelgrove PVR, Grassle JF, Petrecca RF (1994) Macrofaunal response to artificial enrichments and depressions in a deep-sea habitat. J Mar Res 52:345-369

Snelgrove PVR, Grassle JF, Petrecca RF (1996) Experimental

Editorial responsibility: Paul Snelgrove,

St. Johns, Canada evidence for aging food patches as a factor contributing to high deep-sea macrofaunal diversity. Limnol Oceanogr 41:605-614

> Soetaert K, Heip C (1995) Nematode assemblages of deep-sea and shelf break sites in the North Atlantic and the Mediterranean Sea. Mar Ecol Prog Ser 125:171-183

Soetaert K, Muthumbi A, Heip C (2002) Size and shape of ocean margin nematodes: morphological diversity and depth-related patterns. Mar Ecol Prog Ser 242:179-193

Sokal RR, Rohlf FJ (1995) Biometry, 3rd edn. WH Freeman and Company, San Francisco, CA

Thistle D (1978) Harpacticoid dispersion patterns: implications for deep-sea diversity maintenance. J Mar Res 36: $377-397$

Thistle D (1981) Natural physical disturbances and communities of marine soft bottoms. Mar Ecol Prog Ser 6:223-228

Tietjen JH, Deming JW, Rowe GT, Macko S, Wilke RJ (1989) Meiobenthos of the Hatteras Abyssal Plain and Puerto Rico Trench: abundance, biomass and associations with bacteria and particulate fluxes. Deep-Sea Res 36:1567-1577

Tita G, Vincx M, Desrosiers G (1999) Size spectra, body width and morphotypes of intertidal nematodes: an ecological interpretation. J Mar Biol Assoc UK 79:1007-1015

Tomba AM, Keller TA, Moore PA (2001) Foraging in complex odor landscapes: chemical orientation strategies during stimulation by conflicting chemical cues. J N Am Benthol Soc 20:211-222

Tyler PA (1995) Conditions for the existence of life at the deep-sea floor: an update. Oceanogr Mar Biol Annu Rev 33:221-244

Ullberg J, Ólafsson E (2003a) Effects of biological disturbance by Monoporeia affinis (Amphipoda) on small-scale migration of marine nematodes in low-energy soft sediments. Mar Biol 143:867-874

Ullberg J, Ólafsson E (2003b) Free-living nematodes actively choose habitat when descending from the water column. Mar Ecol Prog Ser 260:141-149

Warwick RM (1984) Species size distributions in marine benthic communities. Oecologia 61:32-41

Warwick RM, Clarke KR (1993) Increased variability as a symptom of stress in marine communities. J Exp Mar Biol Ecol 172:215-226

Wieser W (1953) Die Beziehung zwischen Mundhöhlengestalt, Ernährungsweise und Vorkommen bei freilebenden marinen Nematoden. Arch Zool 4:439-484

Wieser W (1959) The effect of grain size on the distribution of small invertebrates inhabiting the beaches of Puget Sound. Limnol Oceanogr 4:181-194

Zhou H (2001) Effects of leaf litter addition on meiofaunal colonization of azoic sediments in a subtropical mangrove in Hong Kong. J Exp Mar Biol Ecol 256:99-121

Zuckerman BM, Jansson HB (1984) Nematode chemotaxis and possible mechanisms of host/prey recognition. Annu Rev Phytopathol 22:95-113

Submitted: December 6, 2007; Accepted: April 23, 2008

Proofs received from author(s): September 3, 2008 